\title{
Intraspecific interference among foraging blue crabs Callinectes sapidus: interactive effects of predator density and prey patch distribution
}

\author{
Mary E. Clark ${ }^{1, *}$, Thomas G. Wolcott ${ }^{1}$, Donna L. Wolcott ${ }^{1}{ }$ Anson H. Hines ${ }^{2}$ \\ 'Department of Marine, Earth, and Atmospheric Sciences, North Carolina State University, Raleigh, \\ North Carolina 27695, USA \\ ${ }^{2}$ Smithsonian Environmental Research Center, 647 Contee's Wharf Road, Edgewater, Maryland 21037, USA
}

\begin{abstract}
The interactive effects of predator density and prey distribution on the foraging behavior of an important estuarine predator were studied, at a fine temporal scale, using ultrasonic telemetry. The movement and agonistic activity of individual blue crabs Calinectes sapidus were monitored in large field enclosures, in which the density of crabs and the distribution of patches of bivalve prey Macoma balthica were varied. Agonism-related injury in blue crabs is common and may be quite costly. On a scale of days, blue crabs have been shown in previous studies to disperse, sometimes into prey-impoverished areas, in response to conspecific interference. On the scale of minutes to hours addressed in the present study, the density of predators and the distribution of their prey interacted to affect the foraging behavior and success of blue crabs. When only a single clam patch was available, blue crabs at high density interfered with each other's foraging by direct agonistic encounters, shown by an inverse correlation between agonistic activity and foraging success. Conversely, when prey were partitioned into 2 patches, blue crabs at high density apparently dispersed among the patches, thus minimizing direct agonistic clashes. Although crabs reduced the occurrence of agonistic encounters further than the $50 \%$ attributable to their effectively halving their densities on each patch, they did not take refuge in the prey-impoverished areas between experimental patches for significant periods. Instead, they seemed to respond instantaneously to changing degree of risk by moving off the clam patch when another conspecific approached.
\end{abstract}

KEY WORDS: Foraging A Agonism - Callinectes sapidus - Macoma balthica - Ultrasonic telemetry Chesapeake Bay

\section{INTRODUCTION}

Density of predators, distribution of prey resources, and the interaction of these factors have important effects on the foraging behaviors of many animals. When prey resources are patchy, predators often aggregate on patches in proportion to prey density (Holling 1959, Sutherland 1983). Predators, consequently, can accumulate at very high densities on the most rewarding patches (Holling 1959, Goss-Custard 1977, Goss-Custard et al. 1977, Piatt et al. 1989). As predators become crowded, they may spend more time

\footnotetext{
- Present address: North Carolina State University c/o, 5101 Belgrave Circle, Wilmington, NC 28403, USA.

E-mail:m_clark@iname.com
}

in agonistic interactions and forage less successfully (Goss-Custard 1977, Goss-Custard et al. 1984). Predators often disperse from areas of high conspecific density to areas where, because of poorer resource quality, there are fewer competitors (Ens \& Goss-Custard 1984, Palumbi \& Freed 1988, Goss-Custard et al. 1992). Many predators have been observed to behave in this manner, although little field-scale research has been undertaken in marine/estuarine subtidal areas.

The estuarine subtidal zone is characterized by highly mobile, agonistic predators, many of which possess formidable weapons (claws, chelae, spines). Blue crabs Callinectes sapidus are an ubiquitous example of such a predator on the Atlantic and Gulf coasts of the United States. The foraging behavior of crabs appears likely to be influenced by both distribution of prey and 
density of other crabs. In controlled field-scale experiments, blue crabs spend disproportionately more time on experimental prey-enriched patches than in surrounding prey-depauperate areas (M.E. Clark unpubl. data), suggesting that they will aggregate at high densities in prey-rich areas. Blue crabs forage less successfully in the presence of many conspecifics than under less crowded conditions in both the laboratory and field (Mansour \& Lipcius 1991, Dittel et al. 1995, Hines \& Ruiz 1995), sometimes because they divert time from foraging into aggressive behaviors (Mansour \& Lipcius 1991, K. Moody \& R. Lipcius pers. comm.). Whether the behavior of crabs foraging under crowded conditions is influenced by prey distribution has been studied indirectly by assessing prey survival (Micheli 1997), but has not been monitored directly in natural surroundings. Because agonism-related injury is expensive to crabs in terms of foraging ability, energy use, growth, options for defense, and mating success (Smith 1990, 1992, \& 1995, Smith \& Taylor 1993), they may have evolved behaviors to utilize multiple prey resources (e.g. multiple patches) in their habitat in ways that minimize agonistic clashes.

Although blue crabs are interesting candidates for study, they are difficult to observe in the often murky water of their estuarine habitats. To determine the movement and aggressive activity of individual crabs in a field-scale setting, a customized ultrasonic telemetry system was developed. This system monitored the spreading of the chelae in the agonistic display, the 'lateral merus' or 'meral spread' posture common to many decapods (Hazlett 1971. Jachowski 1974, Dingle 1983), as an index of aggressive activity. In large field enclosures in a subestuary of the central Chesapeake Bay, individual telemetered crabs were observed while the density of predators as well as the distribution of their bivalve prey Macoma balthica were manipulated. Because of the labor-intensive nature of the telemetry preparations, a single telemetered crab was used as an index of the agonism intensity of all crabs during an experiment in the enclosure. The Rhode River's simple predator-prey complex allows experimental manipulations under controlled, yet realistic, conditions (Hines et al. 1990). Macoma balthica were selected as prey because of their abundance and ecological importance, having major effects on recruitment of infaunal species (Hines et al. 1989). Clams are preferred prey items of crabs, composing up to $50 \%$ of their diets (Hines et al. 1990).

It was hypothesized that as foraging crabs aggregate onto prey patches, they will experience density-related agonistic interference and will show behaviors that minimize agonistic encounters. Behaviors may include dispersing among multiple prey patches ( 2 in the case of this study), seeking refuge for extended periods in the prey-depauperate area between patches, and/or responding instantaneously to small changes in level of risk.

\section{METHODS}

Study site. Experiments were conducted in the Rhode River $\left(38^{\circ} 51^{\prime} \mathrm{N}, 76^{\circ} 32^{\prime} \mathrm{W}\right)$, a 485 hectare subestuary of the central Chesapeake Bay, during the summers of 1992 through 1994. To control abundance of predators and availability of prey resources, all experiments were conducted in $20 \times 20 \mathrm{~m}$ field enclosures. The walls of enclosures were $4 \mathrm{~cm}$ VEXAR mesh that extended above the high-tide line and were edged on the bottom with galvanized wire that extended several centimeters below the sediment surface. Enclosures were near shore (water depth = 1 to $2.5 \mathrm{~m}$ ) in the upper reaches of the river adjacent to the grounds of the Smithsonian Environmental Research Center (SERC). Sediment in enclosures was mainly fine, silty mud with some sandy areas in the near-shore corners.

Adult crabs in addition to those experimentally introduced in enclosures were frequently trapped by crab pots deployed following experiments. The majority of these animals had recently molted, suggesting that they had passed through the fencing as juvenile instars and thus had not interacted competitively with experimental animals during the experiment.

To create patches of clams, 10 fixed wooden frames of approximately $1 \mathrm{~m}^{2}$ were embedded within the central $10 \times 10 \mathrm{~m}$ area of the enclosure. The frames received two $50 \times 100 \mathrm{~cm}$ plastic bins filled with $30 \mathrm{~cm}$ of control or prey-enriched sediment, such that the sediment surface of the 'patch' was flush with the surrounding natural sediment.

Naturally occurring ('background') prey were scarce in the enclosures. The most common bivalves, Macoma balthica and Macoma mitchelli ( $<1.5 \mathrm{~cm}$ shell width), occurred at densities of only a few clams per square meter as estimated by random sediment cores. Juvenile crabs were rare in most trials and, being much smaller than experimental predators, were considered potential prey rather than competitors (Hines \& Ruiz 1995).

Experimental specimens. Crabs were collected by trap and otter trawl. Intermolt males (130 to $170 \mathrm{~mm}$ carapace width) that possessed at least both chelipeds, both swimming paddles, and most walking legs were selected for experiments. In each experiment, an individual crab having all limbs was fitted with a telemetry transmitter that allowed monitoring of the crab's location and agonistic behavior. Prior to experiments, crabs were held in $2000 \mathrm{I}$ outdoor tanks with $10 \mathrm{~cm}$ deep 


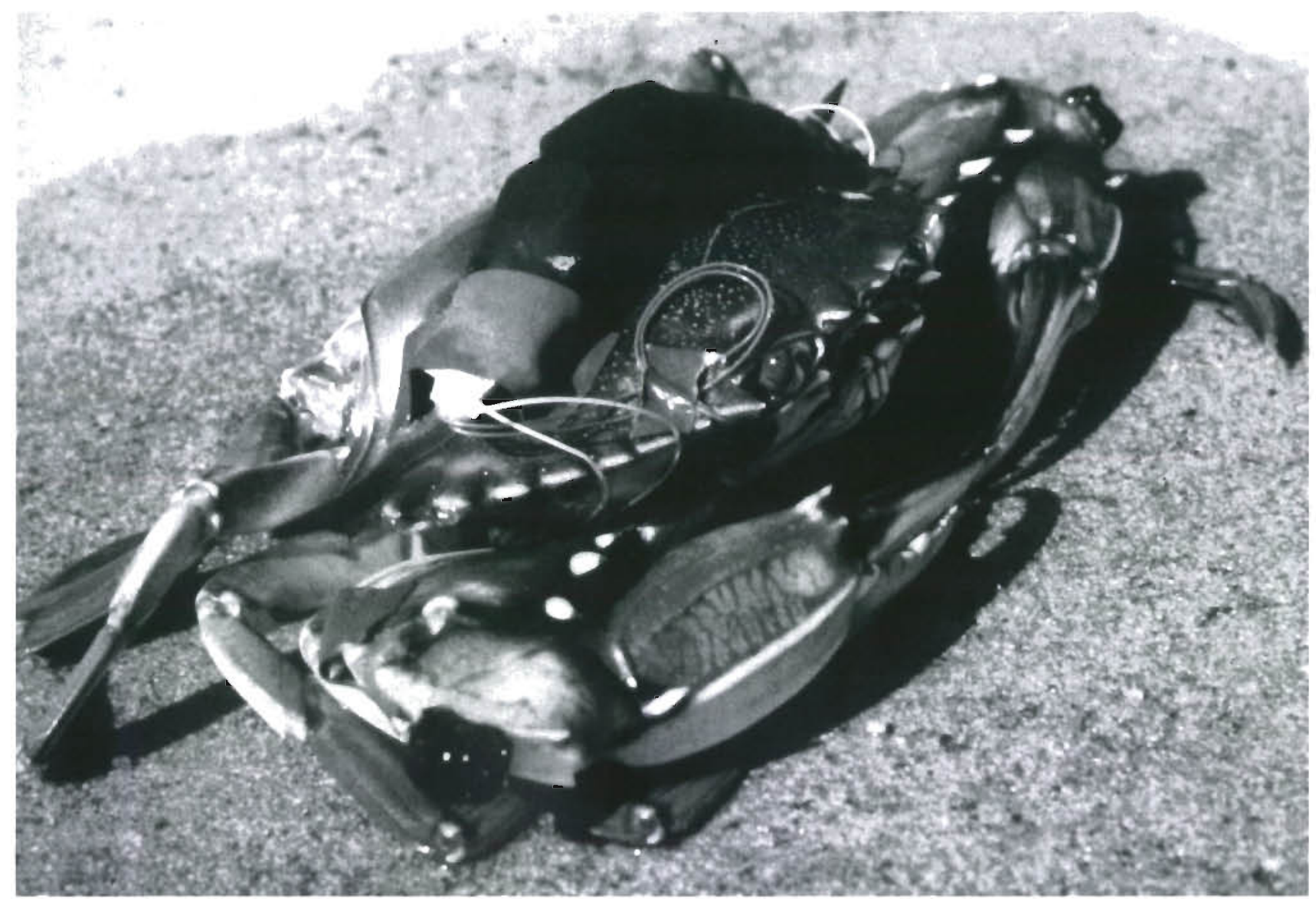

Fig. 1. Photograph of crab outfitted with a telemetry transmitter, showing preparation to monitor threat display activity (meral spread). On crab's chelae: reed-switches are secured to each dorsum of each merus, and magnets to each carpus

flowing estuarine water and observed periodically for about $48 \mathrm{~h}$ to verify health and vigor. Crabs were fed ad libitum with clams and frozen fish up until $24 \mathrm{~h}$ before they were added to experimental enclosures.

The telemetry system used in 1992 and 1993 allowed monitoring of agonistic behavior (as indicated by the 'meral spread' display) and crab location. The transmitters were modified versions of those used in previous experiments to detect molting (Wolcott \& Hines 1990 Shirley \& Wolcott 1991). The electronics were packaged in electrical sleeving ('shrink tubing'), contoured to conform to the dorsal carapace (to minimize drag). and filled with corn oil to couple sound from the trans. ducer to the water. Transmitters were lashed transversely on the dorsal carapace using no. 18 (AWG) copper wire twisted around the lateral spines. Transmitters weighed approximately $20 \mathrm{~g}$ in air $17 \mathrm{~g}$ in water), and had no obvious effects on behavior of crabs.

The meral spread display was signaled only when both chelae were extended, to distinguish it from other postures (swimming, feeding) in which extension of 1 chela is common, but extension of both is rare. The dis- play was sensed with waterproof reed switches fastened to the dorso-medial surfaces of the merus of each chela with a rubber membrane (dental dam) and cyanoacrylate glue (Hysol ${ }^{\circledR}$ 2-C-500). On each carpus, a magnet was positioned so that it would energize the adjacent switch when the chela was extended. The 2 switches were wired in series, closing the circuit only if both chelae were extended (Fig. 1). The meral spread display was reported as a percentage of time spent in display (originally recorded as seconds of display per minute) rather than as frequency of display events (onsets). The former is more relevant ecologically, given that crabs sometimes display continuously for up to 6 min (M.E. Clark unpubl. data). Also, the telemetry system provided a more reliable measurement of duration of displays than of start/stop frequency.

Clams were collected by suction dredge. Only intact individuals (20 to $30 \mathrm{~mm}$ shell width) with a vigorous siphon-retraction reflex were selected for experiments. Clams were held on sea tables irrigated by flowing estuarine water until they were deployed in experimental enclosures. 
Table 1. Dates and locations of manual telemetry experiments

\begin{tabular}{|c|c|c|c|c|c|c|c|}
\hline \multicolumn{8}{|c|}{ Prey distribution/Predator density } \\
\hline \multicolumn{4}{|c|}{ Single prey patch (1992) } & \multicolumn{4}{|c|}{ Two prey patches $(1993)$} \\
\hline \multicolumn{2}{|c|}{ Low density } & \multicolumn{2}{|c|}{ High density } & \multicolumn{2}{|c|}{ Low density } & \multicolumn{2}{|c|}{ High density } \\
\hline Date $(\mathrm{mo} / \mathrm{d})$ & Enclosure & Date $(\mathrm{mo} / \mathrm{d})$ & Enclosure & Date $(\mathrm{mo} / \mathrm{d})$ & Enclosure & Date $(\mathrm{mo} / \mathrm{d})$ & Enclosure \\
\hline \multirow[t]{2}{*}{$7 / 29-30$} & $\# 2$ & $7 / 29-30$ & $\# 3$ & $7 / 15-16$ & $\# 1$ & $7 / 15-16$ & $\# 3$ \\
\hline & & $8 / 19-20$ & \#1 & $7 / 22-23$ & \#3 & $7 / 22-23$ & \#2 \\
\hline $8 / 28-29$ & $\# 2$ & & & & & $8 / 13-14$ & \#3 \\
\hline \multirow{2}{*}{$9 / 2-3$} & $\# 3$ & $9 / 2-3$ & \#1 & $8 / 19-20$ & \#3 & $8 / 19-20$ & \#1 \\
\hline & & $9 / 16-17$ & $\# 3$ & $9 / 17-18$ & \#3 & & \\
\hline $9 / 23-24$ & $\# 3$ & & & & & & \\
\hline
\end{tabular}

Study design. The study design included 2 treatments of predator density: low ( 2 crabs per enclosure), and high (8 crabs per enclosure). Crabs were added to enclosures after the clam patches were deployed, and given $24 \mathrm{~h}$ to acclimate before experiments were started. The study design also included 2 treatments of prey patch availability: a single clam patch $\left(1 \mathrm{~m}^{2}\right.$ patch of 45 clams), and a pair of patches (two $1 \mathrm{~m}^{2}$ patches of 45 clams each, separated by about $15 \mathrm{~m}$ ). The density of prey in patches was relatively low, given that densities in excess of 100 clams per square-meter can be found in the Rhode River (Hines et al. 1990). This experimental density, rather than a higher one, was used to promote interactions among predators on the patch. This density, however, was high enough so that predators would not be expected to deplete the patches during the experiment. The single patch was deployed in 1 site randomly chosen from the 10 fixed patch sites. A patch to control for mortality not caused by predation was deployed in another randomly selected site, and covered with $1 \mathrm{~cm}$ mesh, galvanized wire. The 2-patch experiments were set up using diagonally opposed corner patch sites, and placement of clam patches in successive experiments alternated between the 2 possible diagonal configurations; on occasion, a third patch (control) was placed in another of the 10 fixed patch sites. Clams in both treatments were planted, by SCUBA divers, about $10 \mathrm{~cm}$ deep in the sediment. Patches were then covered with $1 \mathrm{~cm}$ galvanized-wire mesh for $24 \mathrm{~h}$, so that clams had time to bury deeper and to extend their siphons to the sediment surface while protected from predation. At the end of this acclimation period, patch covers were removed from the experimental (but not control) patches.

Eight trials using the single-patch treatment were conducted during summer 1992, 4 at low predator density and 4 at high density. Eight trials using the 2-patch treatment were conducted during summer 1993, 4 at low predator density and 4 at high density. During both summers, trials were cycled among 3 experimental enclosures. Ideally, a low- and high-density trial were to be executed nearly simultaneously (on consec- utive days) in 2 different enclosures. However, several trials were excluded because of equipment failures. The 16 trials ultimately analyzed were conducted on the dates shown in Table 1.

Observations. To observe the movement and agonistic activity of predators, the signal coming from the telemetered crab in the enclosure was monitored during the time periods of 06:00 to 08:30 and 15:30 to 19:00 $h_{i}$ these are periods previously identified as peaks of feeding and aggressive activity of crabs in the field (Clark et al. 1999). During each trial, a single telemetered crab was used as an index of the agonism intensity of all crabs in the enclosure. To track movements of crabs, the observer used an ultrasonic receiver (Sonotronics ${ }^{(1)}$ USR-5) and directional hydrophone from a small boat just outside the enclosure fencing, triangulating on the crab's transmitter. The observer also listened for increases in rate of the transmitter pulse, indicating that the crab was in meral spread posture. Movements of crabs as well as time, duration, and location of meral spread displays were recorded manually on a waterproof chart of the enclosure. (Fig. 2 shows a sample movement track of a crab in the enclosure.) Foraging success was evaluated using SCUBA to excavate bins of clams after crabs had fed from them for $24 \mathrm{~h}$. Clams were censused (number live and number dead from causes other than predation) by sieving the sediment of each patch through $1 \mathrm{~cm}$ wire mesh.

To observe the fine-scale behavior of 2 crabs simultaneousiy, a novel automated telemetry system was utilized. The digital transmitters used with the automated telemetry system were similar in size and appearance to those used with the manual system. These transmitters weighed $29 \mathrm{~g}$ in air ( $15 \mathrm{~g}$ in water). The automated system relied on 8 bit digital encoding to telemeter meral spread and individual identification codes simultaneously (Wolcott \& Hines 1996). Logging of data depended on digital encoding that required a microcontroller-based interface and a lap-top computer. Sixteen automated telemetry trials (using the 2-patch design) were conducted during summer 1994. (These trials were also intended to explore the effects of the 


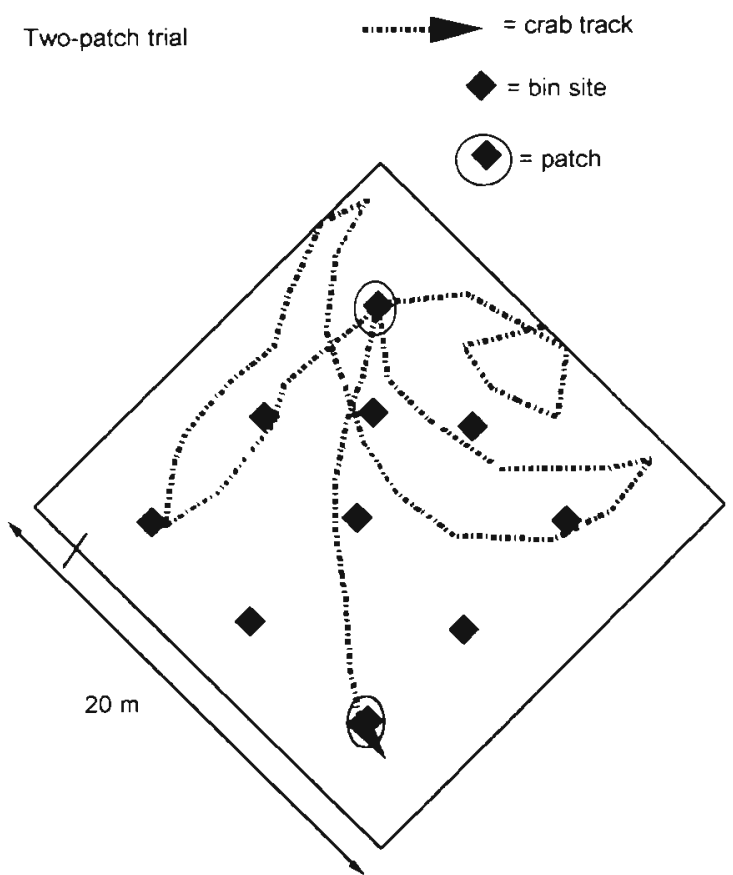

Fig. 2. Movement pattern of crabs within enclosures: sample track

predator density treatments; however, difficulties in maintaining the integrity of the experimental enclosures in the 1994 field season precluded such analyses.)

Statistical analyses. Because of the focus on the interaction between predator density and prey patch distribution, the data were pooled across years (i.e. single-patch trials from 1992 and 2-patch trials from 1993). Although this is not the preferred design, analyzing the data as a single set is justified for a number of reasons. Key variables were uniform among years Most importantly, densities of background prey in enclosures (clams, juvenile crabs) were uniformly low among years. The physical layout of the experimental system and techniques did not change. Physical variables (e.g. temperature, salinity, turbidity) were more variable within years than among years. Overall responses of crabs (e.g. movement rate, temporal pattern of agonism) were similar between years.

A 2-way ANOVA procedure, with predator density and prey distribution as factors, was used to analyze the following response variables: agonism as estimated by the percentage of time that the crabs spend in meral spread displays, movement rate $\left(\mathrm{m} \mathrm{h}^{-1}\right)$, and percentage of time crabs spend on prey patches. If the interaction of factors was significant, a 1-way ANOVA was used to analyze the response variables within each factor. Where data were not distributed normally or variances were not homogeneous, a nonparametric test or the Welch ANOVA method was used (Welch 1951), respectively.
A chi-square test was used to compare the observed and expected values of the following variables: amount of meral spread activity occurring on or near prey patches, and occurrence of meral spread activity when a second prey patch was added.

Linear regression was used to analyze the following correlations: (1) length of time (min) of a crab's visit to the clam patch regressed against the occurrence of meral spread displays during that visit, (2) collective foraging success (clams/crab) regressed against the meral spread activity ( $\%$ of observation time) of a telemetered crab, and (3) length of time (s) of a crab's visit to the clam patch regressed against the distance (m) to another crab. In model (3), an interaction term to control for individual predator effect was included; SAS Type-III sum of squares was used to assess the significance of the main effect.

All data are presented in the text as mean \pm SE.

\section{RESULTS}

\section{Relationship between predator density and} agonistic activity

Foraging crabs engaged in a disproportionately high amount of agonistic activity on or near prey patches, suggesting that crabs are aggregating around the patches and experiencing density-related interference. Crabs engaged in a significantly greater percentage of meral spread displays on or near prey patches $(37.32 \pm 9.99 \%)$ than expected based on the $3.14 \%$ (or $6.28 \%$ in the 2 -patch trials) of enclosure area covered by patch and near-patch areas (Fig. 3).

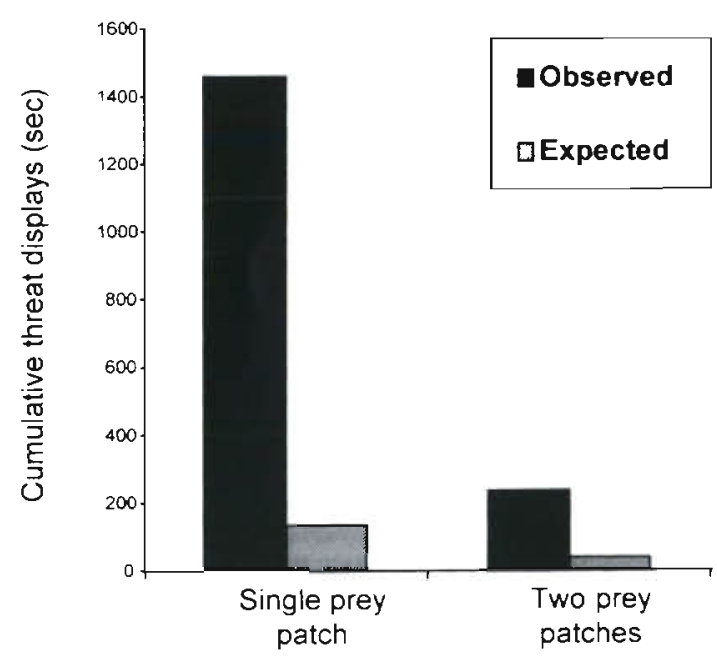

Fig. 3. Cumulative amount of meral spread display (in seconds) on or near prey patches versus that expected based on percentage of enclosure covered by these areas (chi-square test, $\left.\chi^{2}[3]=14,135, \mathrm{p}<0.0001\right\}$ 
Table 2. F-values for main effects (predator density, prey distribution) and interaction in 2-way ANOVA

\begin{tabular}{|c|c|c|c|}
\hline \multirow[t]{2}{*}{ Dependent variable } & \multicolumn{3}{|c|}{ Treatment } \\
\hline & Predator density & Prey distribution & Predator density $\times$ Prey distribution \\
\hline Occurrence of agonism ( $\%$ of obs. time) & $16.41 \cdots$ & $13.15^{\circ}$ & $8.56^{\circ}$ \\
\hline Rate of movement $\left(\mathrm{m} \mathrm{h}^{-1}\right)$ & $4.73^{\circ}$ & $0.82^{\mathrm{NS}}$ & $1.11^{\mathrm{NS}}$ \\
\hline Time on prey patches ( $\%$ of obs. time) & $0.31^{\mathrm{NS}}$ & $0.02^{\mathrm{NS}}$ & $0.08^{\mathrm{NS}}$ \\
\hline $\mathrm{NS}=$ not significant $_{i} \cdot \mathrm{p} \leq 0.05 ; \cdots p \leq 0.01$ & & & \\
\hline
\end{tabular}

Interference among crabs was further supported by the observations that they engaged in more agonistic activity as their density increased (Table 2), and foraged less successfully as the amount of time spent in agonistic encounters increased. Crabs participated in significantly more agonistic encounters in the high predator density treatment (2.93\% of time) than in the low predator density treatment $(0.32 \%$ of time) (Wilcoxon signed-rank test, $z(8)=2.10, p<0.05$ ). When only a single clam patch was available, an inverse correlation emerged between agonistic activity and foraging success for crabs at high density (Fig. 4).

\section{Relationship between distribution of prey and agonistic activity of predators}

When crabs were presented with multiple prey options (i.e. 2 prey patches instead of 1), they appeared to engage in behaviors that reduced the amount of aggressive encounters and the subsequent impact on foraging ability. Crabs demonstrated significantly less meral spread activity when 2 patches

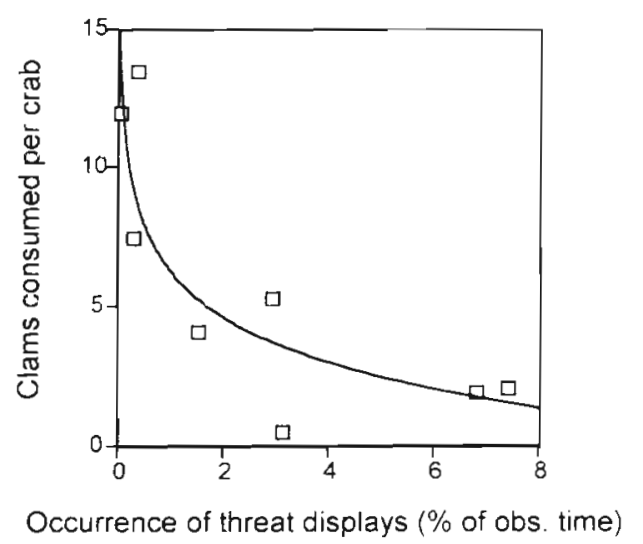

Fig. 4. Occurrence of meral spread displays (\% of observation time) in individual crabs in trials using a single prey patch versus collective foraging success (clams eaten per crab) in that trial. $y=-5.392 \log (x)+6.214, \mathrm{R}^{2}=0.74, \mathrm{n}=8 ; F(1,6)=$ $17.18, p<0.01$. Mortality of prey in control patches was uniformly low (less than $5 \%$ ) across all treatments, so no correction factor was needed for mortality due to causes other than predation by experimental predators were available $(0.45 \%$ of time) than when only 1 clam patch was available $(2.80 \%$ of time). The reduction in aggression appeared to be more than a function of the doubling of total available patch area. The mean occurrence of meral spread display by crabs in 2-patch trials dropped to $16.1 \%$ of the level seen in the singlepatch trials, much less than the $50 \%$ attributable to an effective halving of the crab density on a given patch (Fig. 5). The association between predator density and agonistic activity was suppressed in the 2-patch trials, further suggesting that crabs at high density escape agonistic encounters by using the alternative patch. In trials with only a single clam patch, crabs in the high predator density treatment had a significantly greater occurrence of meral spread display $(5.05 \%$ of time) than crabs in the low predator density treatment $(0.53 \%$ of time). In trials with 2 clam patches, the dif-

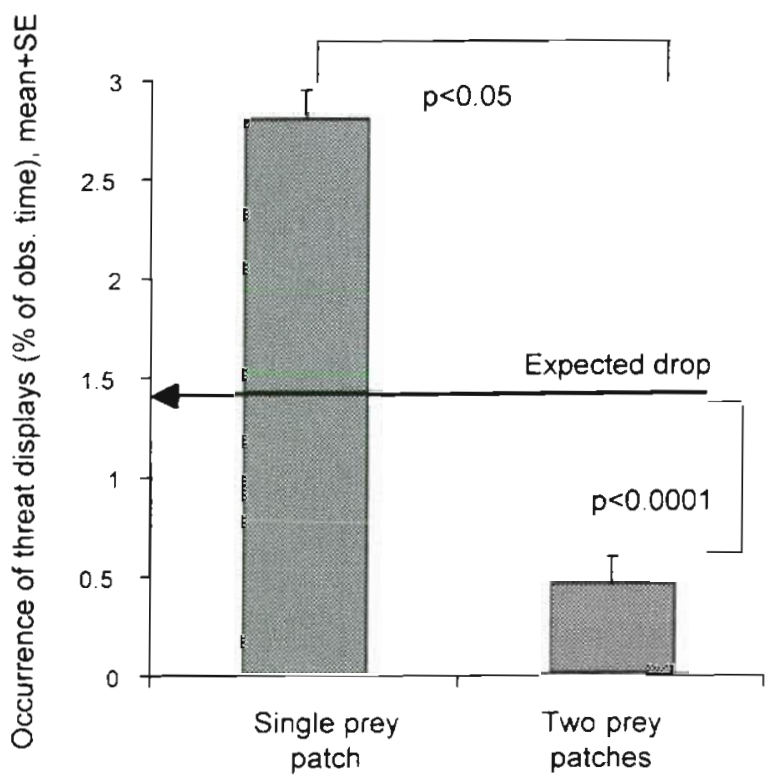

Fig. 5. Meral spread displays (\% of observation time) by crabs in trials with a single prey patch versus in trials with 2 prey patches; Wilcoxon signed-rank test, $z(8)=-2.15, p<0.05$. Occurrence of meral spread display by crabs in 2-patch trials dropped to $16.1 \%$ of the level seen in the single-patch trials. less than the $50 \%$ expected (chi-square test using cumulative seconds of meral spread display, $\chi^{2}[1]=883, p<0.0001$ ) 


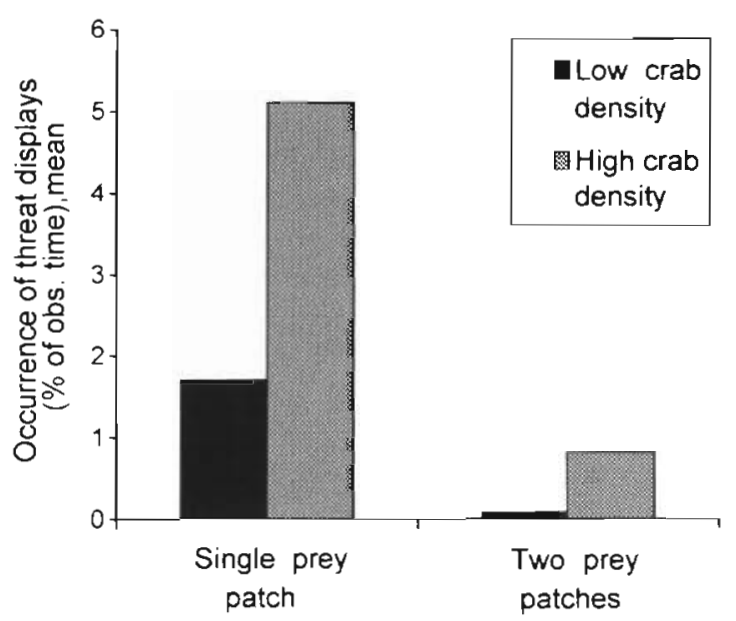

Fig. 6. Meral spread activity ( $\%$ of observation time): Effect of crab density and distribution of prey patches. In trials with a single clam patch, crabs in the high predator density treatment had a significantly greater occurrence of meral spread display than crabs in the low predator density treatment; 1 way Welch ANOVA, $F(1,6)=13.60, p<0.05$. In trials with 2 clam patches, the difference was not significant; 1 -way Welch ANOVA, $F(1,6)=2.75, \mathrm{p}=0.20$

ference was not significant between crabs in the high predator density treatment $(0.82 \%$ of time in meral spread) and those in the low predator density treatment $(0.08 \%$ of time in meral spread) (Fig. 6). As agonistic activity was minimized in the 2-patch trials, its importance as a factor determining foraging success was lessened. The inverse correlation between agonistic activity and foraging success, that had been observed in the single-patch design, disappeared when an alternative patch was available $(F[1,6]=$ 3.23, $p=0.12$ ).

\section{Dispersal of predators among prey patches}

The observed movement of crabs within the enclosures suggests that crabs travel among multiple prey patches as one way of reducing agonistic encounters. Crabs had a significantly greater rate of movement in the high predator density treatment $\left(9.12 \pm 2.40 \mathrm{~m} \mathrm{~h}^{-1}\right)$ than in the low predator density treatment $(3.48 \pm$ $1.20 \mathrm{~m} \mathrm{~h}^{-1}$ ) (Table 2). Although some of this increase may reflect evasive maneuvering among crabs, that movement rate appeared linked to crab density only when 2 patches were present is consistent with interpatch transit. In the single-patch treatment, crabs did not move at a significantly greater rate in the high predator density treatment $\left(6.60 \pm 2.99 \mathrm{~m} \mathrm{~h}^{-1}\right)$ than in the low predator density treatment $\left(3.68 \pm 2.38 \mathrm{~m} \mathrm{~h}^{-1}\right)$. In the 2-patch treatment, however, crabs moved marginally faster in the high predator density treatment

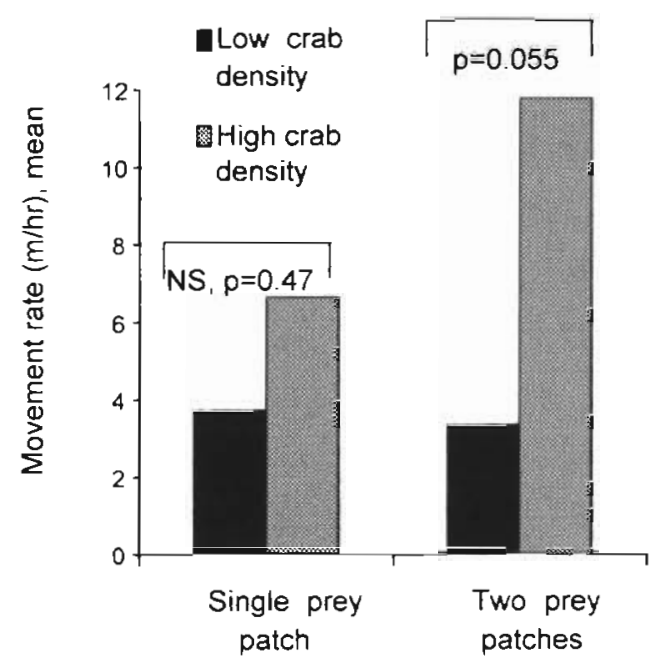

Fig. 7. Movement rate of crabs $\left(\mathrm{m} \mathrm{h}^{-1}\right)$ : Effect of crab density and distribution of prey patches. In the single-patch treatment, crabs did not move significantly faster in the high predator density treatment than in the low predator density treatment (1-way ANOVA, $F[1,6]=0.59, p=0.47$ ). In the 2-patch treatment, crabs moved marginally faster in the high predator density treatment (1-way ANOVA, $F[1,6]=5.63, \mathrm{p}=0.055$ )

$\left(11.70 \pm 3.00 \mathrm{~m} \mathrm{~h}^{-1}\right)$ than in the low predator density treatment $\left(3.30 \pm 1.80 \mathrm{~m} \mathrm{~h}^{-1}\right)$ (Fig. 7).

Although crabs at high density may have moved more among prey patches than did crabs at low density, they did not appear to take refuge in the area between patches for extended periods. Neither prey distribution nor predator density had a significant effect on the percentage of time that crabs spent on clam patches; nor was the interaction term significant (Table 2).

\section{Fine-scale behavior of predators on a prey patch}

Observations of fine-scale movements around a given prey patch indicate that crabs are responsive to instantaneous changes in level of risk. When another crab was within 4 to $5 \mathrm{~m}$ of the prey patch, the crab on the patch appeared to make a relatively short visit to the patch. Within a $5 \mathrm{~m}$ radius, the closer another crab was, the shorter was a crab's visit to the clam patch (Fig. 8). However, there was no significant correlation between length of a visit to the clam patch and the occurrence of meral spread display during that visit $(F[1,20]=0.17, \mathrm{p}=0.69)$.

\section{DISCUSSION}

The density of predators and the distribution of their prey patches interact to affect the foraging behavior of the blue crab, an aggressive estuarine predator. As the 
a

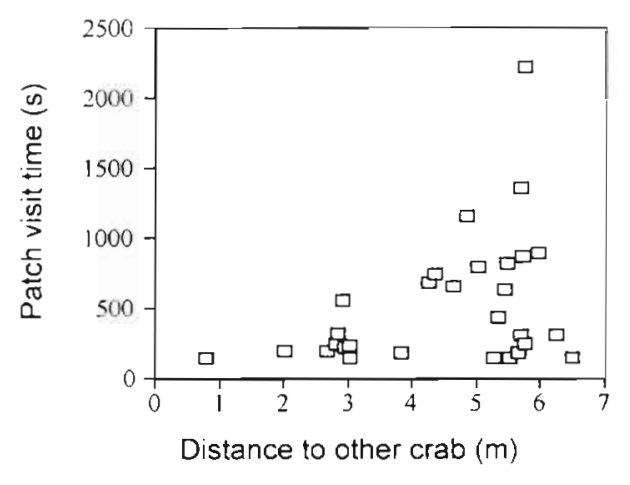

b

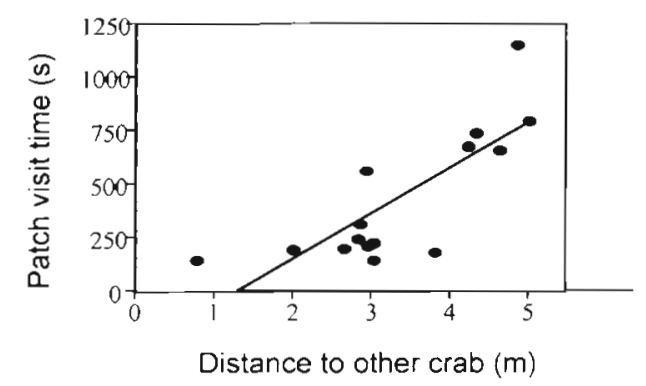

Fig. 8. (a) Duration of visit to clam patch (s) versus distance to another crab $(\mathrm{m})$ : all points. Observations are from 4 crabs, with a total of 29 patch visits. NB: A group of distant points (>14 $\mathrm{m}$ away) are omitted from the plot since they probably represent times when the other telemetered crab was feeding on the alternative clam patch. (b) Duration of visit to clam patch (s) versus distance to another crab (m): when another telemetered crab was within $5 \mathrm{~m}$. Observations are from 3 crabs, with a total of 15 patch visits. ANOVA, $y=$ Duration of a visit to the clam patch, $x=$ Distance to another crab, $F(1,9)=$ $6.29, p<0.05 ; y=-588.11+239.20 x, R^{2}=80$

density of crabs increases, their foraging success falls, whether prey are presented as a single clam patch or as 2 alternative patches (M.E. Clark, T.G. Wolcott, D.L. Wolcott, A.H. Hines unpubl. data). However, this study suggested that the way in which crabs are affected by crowding depends on the distribution of clam patches. Blue crabs foraging at high density appeared to make use of an alternative prey patch as 1 way of minimizing agonistic clashes. Dispersing among multiple prey patches is a behavior that is common to many agonistic predators in other systems (Ens \& Goss-Custard 1984, Palumbi \& Freed 1988, Goss-Custard et al. 1992).

To determine how crabs were disproportionately reducing the occurrence of agonistic encounters when 2 prey patches were available, the fine-scale behavior of crabs on a given prey patch was observed. At this scale, crabs seemed to respond instantaneously to changing levels of risk. Crabs observed with a highresolution autotelemetry system appeared aware of one another within a 4 to $5 \mathrm{~m}$ radius and made a relatively short visit to the prey patch when another crab was near. Although crabs spent as much total time on patches at high density, they probably took several short visits rather than fewer long ones. As crabs increasingly fragment their patch visits, they may retrace previously searched areas of the patch when they return and thereby sustain losses in foraging success. There were insufficient autotelemetry data to test this explicitly. Paradoxically, crabs observed with the manual telemetry system seemed to stay on patches just as long at any given visit at high predator density as at low density (E. Clark, T.G. Wolcott, D.L. Wolcott, A.H. Hines unpubl. data); this apparent discrepancy may have been more a function of study technique than of crab behavior. The relatively coarse resolution of the manual telemetry system (changes of a few meters were detectable) would not have been able to detect the fine-scale 'skirting' of the edge of the patch that was detected in later trials with the automated system (changes of approximately $20 \mathrm{~cm}$ were detectable). That crabs also spent just as much time on the clam patch when agonistic activity was intense also seems inconsistent; however, the time spent on the prey patch is probably an interaction of many factors including density of prey and hunger level of the crab.

Given the high turbidity of water at the site of this study, crabs seem most likely to detect each other by mechanoreception of hydrodynamic disturbances or by chemoreception. Blue crabs can generate directed currents ancillary to gill ventilation or by using the swimming paddles. Although a waterborne chemical cue in the Rhode River's slow currents seems unlikely to be detectable at a distance of $5 \mathrm{~m}$, a cue that is ejected rather than diffused from a hostile animal might be detectable at this range. In fact, several crustaceans forcibly eject urine from their nephropores during provocation (Barron \& Hazlett 1989, Smith \& Taylor 1993).

Presumably because of their ability to assess instantaneous changes in level of risk, blue crabs in this study apparently did not make some relatively longlasting shifts in behavior commoniy associdted with foraging under risk. For example, some foragers (e.g. zooplankton, nudibranchs, salmon) reduce exposure to risk by slowing movement rate or remaining stationary, effectively reducing encounters with predators or conspecifics (MacLeod \& Valiela 1975, Gerritsen \& Strickler 1977, Metcalfe et al. 1987). Others (e.g. several species of birds) reduce their vulnerability to attack while foraging by broadening their diet and/or choosing smaller prey, thus reducing time spent searching for and/or handling prey items (Valone \& Lima 1987. Lima 1988), or by spending more time in prey-impoverished refuge areas (Goss-Custard et al. 
1984, Goss-Custard et al. 1992). Such behaviors were not evident for the blue crabs in this study.

Minimizing agonistic encounters by simply responding to immediate risk of encounter, in lieu of making more long-lasting behavioral changes in high-risk situations, appears adaptive for blue crabs. It probably depresses foraging success less than would limiting time spent in highly profitable areas, including small or poorly digestible prey in the diet, and/or handling prey less efficiently. On the other hand, it has the disadvantage of requiring a forager to react quickly to danger. For blue crabs, this disadvantage is probably minimized by their ability to detect each other from well beyond striking distance while continuing to feed. In this context, blue crabs are different from birds, 1 of the most-studied groups of animals. Unlike birds, which often must look down to feed and up to monitor for predators, blue crabs have sensory modalities that are not compromised during feeding.

Thus, the way that foragers respond to crowding seems to depend, in part, on their ability to assay for changes in risk level while foraging. This ability has been shown to influence the way that various foragers respond to predation risk (Schmitt \& Holbrook 1985 , Lima \& Dill 1990, Lima 1991, Sackley \& Kaufman 1996). For example, when surfperch cannot see well (during crepuscular periods), they make relatively long-lasting changes in behavior (slowing movement rate, moving into refuge areas) when a predator (kelp bass) is present; however, they do not make such changes during daylight hours when they can more readily assess immediate level of risk while feeding (Schmitt \& Holbrook 1985). Hummingbirds also employ risk-lowering behaviors (taking shorter feeding bouts) when at a feeder with an obstructed view, but not when at a feeder with an unobstructed view of potential predators (Lima 1991). Similarly, planktivorous coral reef fish under predation risk feed in the safer, yet nutritionally poorer, zone immediately adjacent to the reef when feeding alone, but feed higher above the reef when they have the benefit of group vigilance (Sackley \& Kaufman 1996).

An issue that needs to be addressed is whether crabs and other invertebrates show such behavioral plasticity in response to risk of predation or aggression. This could be evaluated in blue crabs by observing their response to crowding when their ability to assess instantaneous risk level is compromised. For example, when crabs are foraging at high density in a habitat where they probably can neither see oncoming potential aggressors nor perceive them from waterborne chemical cues or hydrodynamic disturbances, they may tend to make more long-lasting changes in behavior such as slowing their search rate or staying buried more, spending more time in refuge areas (e.g. area between patches), and/or making diet changes. This could be tested experimentally by exposing crabs to a combination of high turbidity (which compromises vision) and high turbulence (which precludes the gleaning of directional information from chemical or hydrodynamic cues) (Weissburg \& Zimmer-Faust 1993).

Acknowledgements. We are grateful to many individuals including G. Braun, J. Gavin, S. Godwin, P. Jivoff, D. Kamykowski, M. Kramer, K. Ruftin, R. Shanks, L.D. Smith, T Steelman, and especially to L. Nye, for advice, manpower, and equipment during the field work. Thanks go to J. Smith for invaluable expertise in statistical programming, to $M$. Gumpertz for statistical consultation, and to S. Mozley for scientific and editorial reviews. This study was supported by research grants to T.G.W. and D.L.W. (NSF Grant OCE9008168) and to A.H. and R.L. (NSF OCE-9000493); by the Smithsonian Environmental Sciences Program; by the Smithsonian Scholarly Studies Program; by a research grant from the Lerner-Gray Fund for Marine Research of the American Museum of Natural History to M.E.C.; by a Predoctoral Research Fellowship from the Smithsonian Institution to M.E.C.; and by funds from the Alumni Association and the Department of Marine, Earth, and Atmospheric Sciences at North Carolina State University.

\section{LITERATURE CITED}

Barron LC, Hazlett BA (1989) Directed currents: a hydrodynamic display in hermit crabs. Mar Behav Physiol 15: $83-87$

Clark ME, Wolcott TG, Wolcott DL, Hines AH (1999) Foraging and agonistic activity co-occur in free-ranging blue crabs (Callinectes sapidus): Observation of animals by ultrasonic telemetry. J Exp Mar Biol Ecol 233 (1):143-160

Dingle H (1983) Strategies of agonistic behavior in Crustacea. In: Rebach S, Dunham DW (eds) Studies in adaptation: the behavior of higher Crustacea. John Wiley \& Sons Inc, New York, p 85-111

Dittel A, Hines AH, Ruiz GM, Ruffin KK (1995) Effects of shallow water refuge on behavior and density-dependent mortality of juvenile blue crabs on Chesapeake Bay. Bull Mar Sci 57(3):903-917

Ens BJ, Goss-Custard JD (1984) Interference among Oystercatchers, Haematopus ostralegus, feeding on mussels, Mytilus edulis, on the Exe Estuary. Anim Ecol 53:217-231

Gerritsen J, Strickler JR (1977) Encounter probabilities and community structure in zooplankton: a mathematical model. J Fish Res Board Can 34:73-82

Goss-Custard JD (1977) Predator response and prey mortality in redshank, Tringa totanus (L.), and a preferred prey, Corophium volutator (Pallas). J Anim Ecol 46:21-35

Goss-Custard JD, Kay DG, Blindell RM (1977) The density of migratory and overwintering redshank, Tringa totanus (L.) and curlew, Homanius arquata (L.), in relation to density of their prey in south-east England. Estuar Coast Mar Sci 5:497-510

Goss-Custard JD, Clark RT, dit Durell SEA le V (1984) Rates of food intake and aggression of oystercatchers, Haematopus ostralegus, on the most and least preferred mussel, Mytjlus edulis, beds on the Exe estuary. J Anim Ecol 53: $233-245$

Goss-Custard JD, Caldow RWG, Clarke RT (1992) Correlates of the density of foraging oystercatchers Haematopus ostralegus at different population sizes. J Anim Ecol 61:159-173 
Hazlett BA (1971) Interspecific fighting in three species of brachyuran crabs from Hawaii. Crustaceana 20:308-314

Hines A.H, Ruiz GM (1995) Temporal variation in juvenile mortality: blue crabs, nearshore shallows, and cannibalism in Chesa peake Bay. Bull Mar Sci 57(3):885-902

Hines AH, Posey MH, Haddon PJ (1989) Effects of adult suspension- and deposit-feeding bivalves on recruitment of estuarine infauna. Veliger 32(2):109-119

Hines AH, Haddon AM, Wiechert LA (1990) Guild structure and foraging impact of blue crabs and epibenthic fish in a subestuary of Chesapeake Bay. Mar Ecol Prog Ser 67: $105-126$

Holling C (1959) Some characteristics of simple types of predation and parasitism. Can Entomol 91:385-398

Jachowski RL (1974) Agonistic behavior of the blue crab. Callinectes sapidus Rathbun. Behav 50:232-253

Lima SL (1988) Vigilance and diet selection: a simple example in the dark-eyed junco. Can J Zool 66:593-596

Lima SL (1991) Energy, predators, and the behaviour of feeding hummingbirds. Evol Ecol 5:220-230

Lima SL, Dill LM (1990) Behavioral decisions made under the risk of predation: a review and prospectus. Can J Zool 68 : $619-640$

MacLeod P, Valiela I (1975) The effect of density and mutual interference by a predator: a laboratory study of predation by the nudibranch Coryphella rufibranchialis on the hydroid Tubularia larynx. Hydrobiologia 47:339-346

Mansour RA, Lipcius RN (1991) Density-dependent foraging and mutual interference in blue crabs preying on infaunal clams. Mar Ecol Prog Ser 72:239-246

Metcalfe NB. Huntingford FA, Thorpe JE (1987) The influence of predation risk on the feeding motivation and foraging strategy of juvenile Atlantic salmon. Anim Bahav 35:901-911

Micheli F (1997) Effects of predator foraging behavior on patterns of prey mortality in marine soft bottoms. Ecol Monogr 67(2):203-224.

Palumbi SR, Freed L.A (1988) Agonistic interactions in a keystone predatory starfish. Ecology 69(5): 1646-1627

Piatt JF, Methven DA, Burger AE, McLagan RL, Mercer V, Creelman E (1989) Baleen whales and their prey in a coastal environment. Can J Zool 67:1523-1530

Editorial responsibility: Otto Kinne (Editor),

Oldendorf/Luhe, Germany
Sackley PG. Kaufman LS (1996) Effect of predation on foraging height in a planktivorous coral reef fish. Chromis nitida. Copeia 3:726-729

Schmitt RJ, Holbrook SJ (1985) Patch selection by juvenile black surfperch (Embiotocidae) under variable risk: interactive influence of food quality and structural complexity. J Exp Mar Biol Ecol 85:269-285

Shirley MA, Wolcott TG (1991) A telemetric study of microhabitat selection by premolt and molting blue crabs, Callinectes sapidus (Rathbun) within a subestuary of the Pamlico River, North Carolina. Mar Behav Physiol 19:133-148

Smith IP, Taylor AC (1993) The energetic cost of agonistic behaviour in the velvet swimming crab, Necora (=Liocarcinus) puber (L.). Anim Behav 45:375-391

Smith LD (1990) Patterns of limb loss in the blue crab, Callinectes sapidus, and the effects of autotomy on growth. Bull Mar Sci 46(1):23-36

Smith LD (1992) The impact of limb autotomy on mate competition in blue crabs Callinectes sapidus Rathbun. Oecologia 89(4):494-501

Smith LD (1995) Effects of limb autotomy and tethering on juvenile blue crab survival from cannibalism. Mar Ecol Prog Ser 116:65-74

Sutherland WJ (1983) Aggregation and the 'ideal free distribution.' J Anim Ecol 52:821-828

Valone TJ, Lima SL (1987) Carrying food items to cover for consumption: the behavior of ten bird species feeding under risk of predation. Oecologia 71:286-294

Weissburg MJ, Zimmer-Faust RK (1993) Life and death in moving fluids: Hydrodynamic effects on chemosensorymediated predation. Ecology 74(5):1428-1443

Welch BL (1951) On the comparison of several mean values: an alternative approach. Biometrika 38: 330-336

Wolcott TG. Hines AH (1990) Ultrasonic telemetry of smallscale movements and microhabitat selection by molting blue crabs (Callinectes sapidus). Bull Mar Sci 46(1):83-94

Wolcott TG, Hines AH (1996) Advances in ultrasonic biotelemetry for animal movement and behavior: the blue crab case study. In: Lang MA, Baldwin CC (eds) Methods and techniques of underwater research. Proc Am Acad Underwat Sci Sci Diving Symp. October 12-13, 1996, Smithsonian Institution, Washington, DC, p 229-236

Submitted: November 19, 1997; Accepted: October 27, 1998 Proofs received from author(s): March 3, 1999 